\title{
Duodenal stump fistula following Roux-en-Y gastrectomy, treated with single-balloon enteros- copy using the tulip bundle technique and fibrin glue injection
}

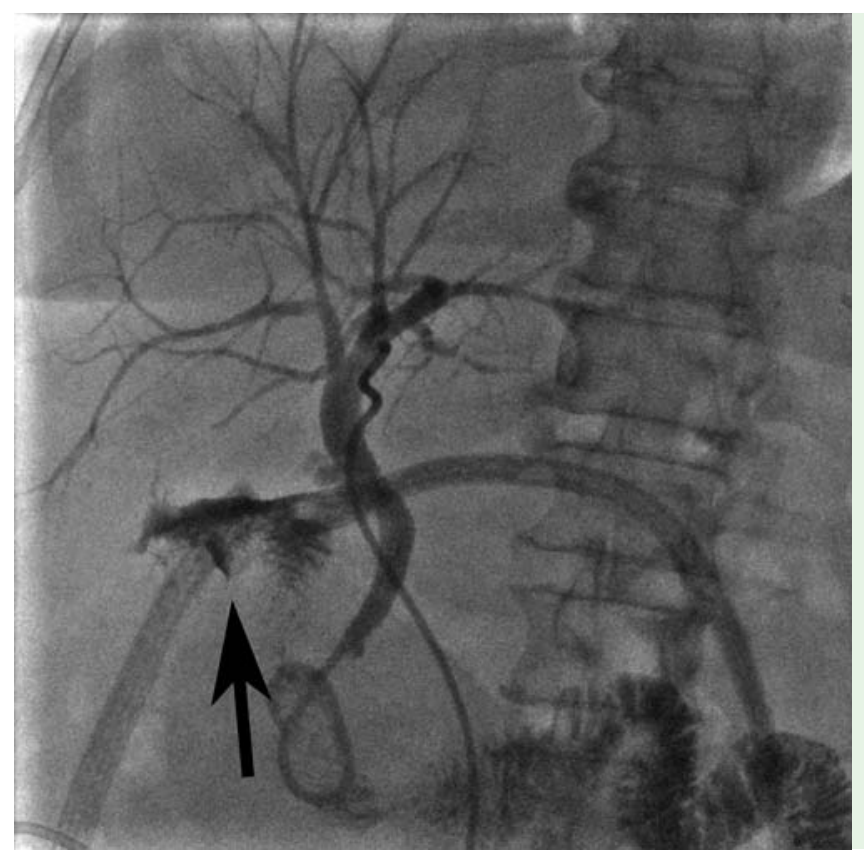

Fig. 1 Percutaneous cholangiography showing a duodenal stump fistula (black arrow) in a 68-year-old woman who underwent laparoscopic partial gastrectomy with Roux-en-Y reconstruction for an ulcerated gastrointestinal stromal tumor.

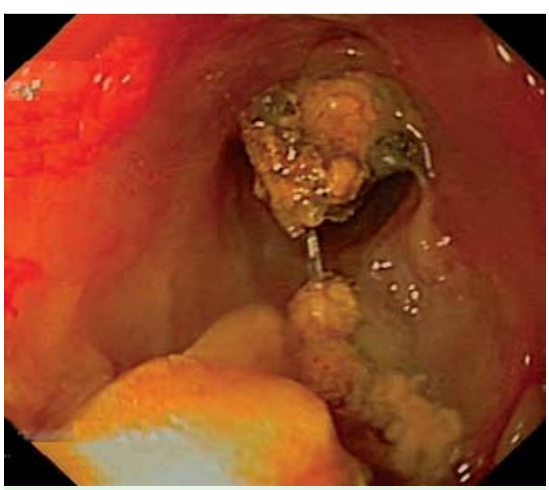

Fig. 2 Endoscopic view of the orifice of the fistula.

In January 2012, a 68-year-old woman underwent laparoscopic partial gastrectomy at our institute, with Roux-en-Y reconstruction for an ulcerated gastrointestinal stromal tumor. The postoperative course was complicated by development of a duodenal stump fistula and subhepatic collection ( $\bullet$ Fig. 1 ). Percutaneous drainage of the collection, as well as percutaneous transhepatic biliary drainage (PTBD), did not reduce the high output leakage. Because of worsening of the patient's clinical condition, and to avoid reintervention, we decided to carry out single-balloon enteroscopy to access the afferent loop and reach the duodenal stump. Informed consent was obtained from the patient.

Single-balloon enteroscopy was carried out with a high resolution enteroscope (SIF-Q180; Olympus America, Center Valley, Pennsylvania, USA) and a disposable sliding overtube (ST-SB1; Olympus America). There was a large, 2-cm orifice surrounded by hyperemic mucosa at the duodenal stump ( $\bullet$ Fig.2). To apply the tulip bundle technique $[1,2]$, eight Resolution Clips (Boston Scientific, Natick, Massachusetts, USA) were placed circumferentially along the periphery of the fistula, and two Endoloops (Olympus America) were placed over the endoclips, near the base, to fully close the fistula ( $\bullet$ Fig.3a-c). We then injected $4 \mathrm{~mL}$ of fibrin glue (Beriplast-P Combi-Set; CSL Behring, Marburg, Germany) into the submucosa to ensure complete sealing of the fistula ( $\bullet$ Fig.3 d-f). Definitive fistula closure was clinically and radiologically observed at the 2 months' follow-up (๑ Fig.4).

Duodenal stump fistula after gastrectomy is a potentially devastating complication, with high morbidity, long period of hospi- talization, and an overall mortality rate of about 20\% (due to sepsis and multiple organ failure) [3]. Treatment with PTBD and an occlusion balloon in the biliary tree has been described $[4,5]$. This report describes a new endoscopic treatment for a refractory duodenal stump fistula and illustrates the feasibility and usefulness of interventional single-balloon enteroscopy. In conclusion, we believe that in the case of a life-threatening complication in the small intestine which is difficult to access, single-balloon enteroscopy may be a viable alternative to surgical intervention.

\section{Endoscopy_UCTN_Code_TTT_1AP_2AD}

Competing interests: None

\section{G. Curcio ${ }^{1}$, R. Badas ${ }^{1}$, R. Miraglia², L. Barresi ${ }^{1}$, I. Tarantino ${ }^{1}$, M. Traina ${ }^{1}$}

${ }^{1}$ Department of Gastrointestinal Endoscopy, Mediterranean Institute for Transplantation and Advanced Specialized Therapies (IsMeTT), Palermo, Italy

2 Department of Radiology, Mediterranean Institute for Transplantation and Advanced Specialized Therapies (IsMeTT), Palermo, Italy

\section{References}

1 Mocciaro F, Curcio G, Tarantino I et al. Tulip bundle technique and fibrin glue injection: unusual treatment of colonic perforation. World J Gastroenterol 2011; 17 (Suppl. 08): $1088-1090$

2 Curcio G, Traina M, Panarello G et al. Refractory gastric ulcer bleeding treated with new endoloop/clips technique. Dig Endosc 2011; 23 (Suppl. 02): 203-204

3 Cozzaglio L, Coladonato M, Biffi R et al. Duodenal fistula after elective gastrectomy for malignant disease. An Italian retrospective multicenter study. J Gastrointest Surg 2010; 14: $805-811$

4 Zarzour JG, Christein JD, Drelichman ER et al. Percutaneous transhepatic duodenal diversion for the management of duodenal fistulae. J Gastrointest Surg 2008; 12: 1103 1109

5 Cozzaglio L, Cimino M, Mauri G et al. Percutaneous transhepatic biliary drainage and occlusion balloon in the management of duodenal stump fistula. J Gastrointest Surg 2011; 15 (Suppl. 11): 1977-1981 


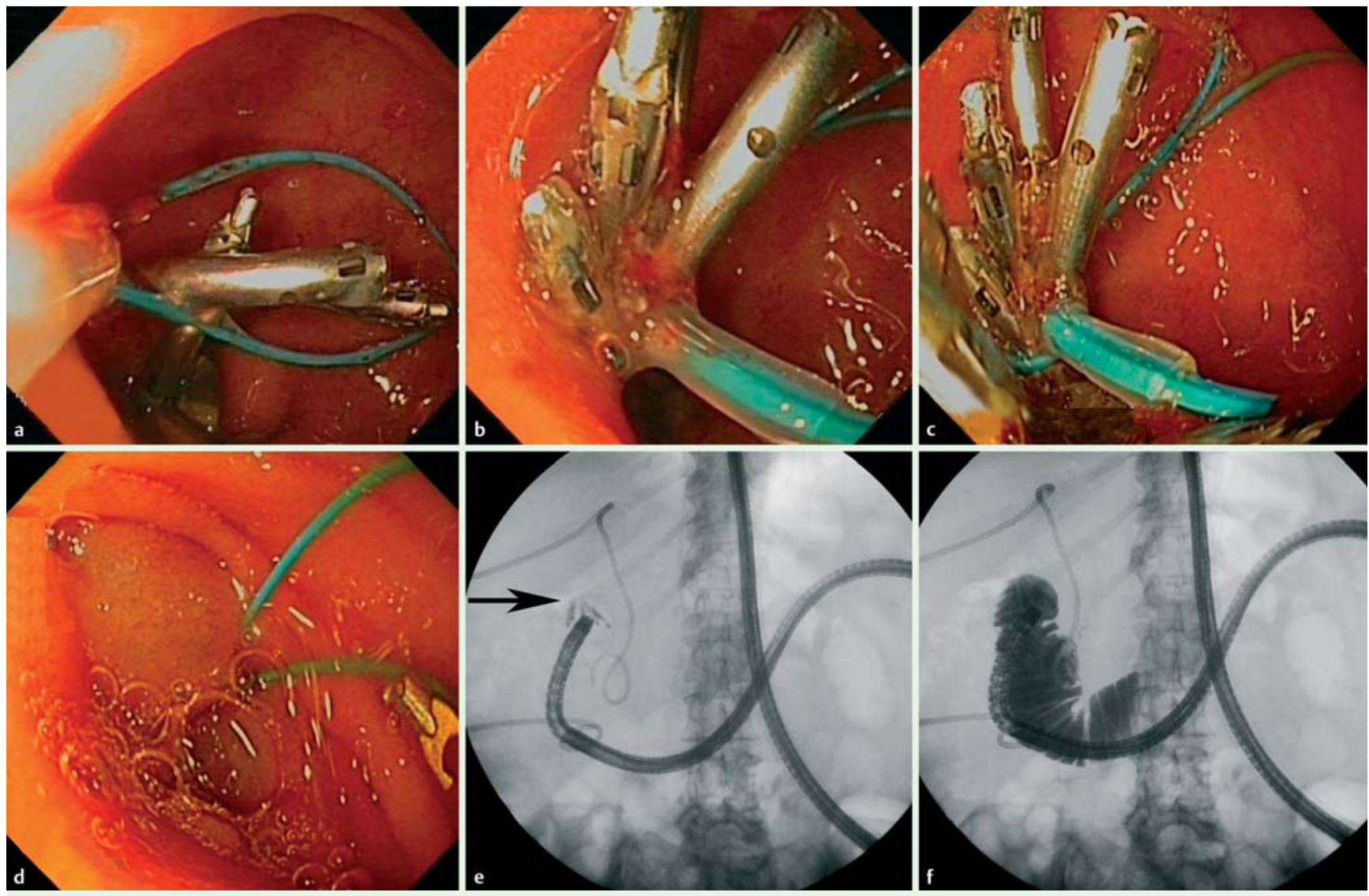

Fig. 3 Endoscopic views: a-c Application of the tulip bundle technique and $\mathbf{d}$ after fibrin glue injection. $\mathbf{e}, \mathbf{f}$ Radiological views at the end of the procedure, before and after contrast dye injection.

Fig. 4 Percutaneous cholangiography showing complete closure of the fistula.
Bibliography

Dol http://dx.doi.org/

10.1055/s-0032-1310073

Endoscopy 2012; 44: E364-E365

(c) Georg Thieme Verlag KG

Stuttgart · New York

ISSN 0013-726X

\section{Corresponding author}

\section{G. Curcio}

Department of Gastrointestinal Endoscopy

IsMeTT, UPMC

Via Tricomi 1

Palermo 90127

Italy

Fax: +39-091-2192400

gcurcio@ismett.edu 